\title{
(2) OPEN ACCESS \\ Foundation for a Smoke-Free World and healthy Indigenous futures: an oxymoron?
}

\author{
Andrew Waa, ${ }^{1,2}$ Bridget Robson, ${ }^{3,4}$ Heather Gifford, ${ }^{5,6}$ Janet Smylie, ${ }^{7,8,9}$ \\ Jeff Reading, ${ }^{10,11}$ Jeffrey A Henderson, ${ }^{12,13}$ Patricia Nez Henderson, ${ }^{13,14}$ \\ Raglan Maddox (1) ${ }^{8,15,16}$ Raymond Lovett, ${ }^{17,18}$ Sandra Eades, ${ }^{19,20}$ \\ Summer Finlay, ${ }^{21,22,23,24}$ Tom Calma, ${ }^{25,26}$ Hāpai Te Hauora Māori Public Health
}

For numbered affiliations see end of article.

\section{Correspondence to}

Dr Raglan Maddox, Centre for Research and Action in Public Health, University of Canberra, Canberra, ACT 2617, Australia; raglan.maddox@canberra. edu.au

Received 15 October 2018 Revised 4 February 2019 Accepted 15 February 2019 Published Online First 10 May 2019

\section{Check for updates}

(C) Author(s) (or their employer(s)) 2020. Re-use permitted under CC BY-NC. No commercial re-use. See rights and permissions. Published by BMJ.

To cite: Waa A, Robson B, Gifford $\mathrm{H}$, et al. Tob Control 2020:29:237-240.
Indigenous peoples represent a diversity of cultures, perspectives and experiences that brings tremendous vibrancy to our world. Within this diversity, many Indigenous peoples share a common history of colonisation that continues today. ${ }^{1}$ We humbly acknowledge and respect that Indigenous people are diverse and constitute many nations, language groups and cultures. For the purposes of this commentary, Indigenous peoples include self-identified individuals and communities who have historical continuity with pre-colonial/pre-settler societies; are strongly linked to their natural environments; and often maintain their own distinct language(s), belief and social systems.

In 2017, Philip Morris International (PMI) provided US $\$ 1$ billion funding for 12 years to establish the Foundation for a Smoke-Free World (the Foundation). The stated purpose of the Foundation is to help achieve a 'smoke free world'. 2 According to the Foundation's Strategic Plan, 'ending smoking' means eliminating use of the cigarette and other forms of combustible tobacco, while ensuring populations affected by this transformation are supported to find sustainable alternative activities and products. ${ }^{3}$ The research agenda includes a focus on an alternative nicotine product version of 'harm reduction'. In August 2018, the Foundation provided a US $\$ 1$ million grant that created a New Zealand-based Centre for Research Excellence: Indigenous Sovereignty and Smoking (the Centre) whose stated aim is to focus on reducing smoking-related harms among Indigenous peoples. ${ }^{45}$

Are the interests of Indigenous peoples truly being served by promoting the research agenda of a tobacco industry-funded Foundation? We do not think so, for several reasons. While improving help for people to cease commercial tobacco use does have potential to reduce the harm from smoked tobacco use, evidence suggests that individually targeted interventions that are essentially palliative and require a significant level of individual agency do not actually address the root cause of the problem. ${ }^{67}$ As such, they do little to address smoking disparities between Indigenous and non-Indigenous peoples. This is demonstrated in papers that have found that despite decades of high-quality population-level (eg, the New Zealand Quitline and media campaigns) and targeted cessation interventions (eg, the Auakati Kai Paipa Smoking cessation services), smoking among New Zealand Māori remains unacceptably high. ${ }^{89}$ It was Māori in Aotearoa (New Zealand) who first advocated for a Tupeka Kore (tobaccofree) country ${ }^{10}$ and emphasised the need to shift attention away from individuals to the true source of the problem: commercial tobacco and the companies that sell and promote it. ${ }^{10}$

Improving physical health is a priority for Indigenous peoples, but this is usually set within the broader context of Indigenous health and wellbeing that connects physical, psychological, social and spiritual health. ${ }^{11}$ The proliferation of alternative nicotine devices (ANDs) and the potential they may hold for improving Indigenous health is a hotly debated topic, ${ }^{12} 13$ and the control of this debate needs to be led by Indigenous peoples and not influenced by external pressures, particularly from organisations that are linked to the tobacco industry. ${ }^{3}$ The prevalence of commercial tobacco use in the general population of Australia, Canada, New Zealand and the USA is $16 \%$, $18 \%, 16 \%$ and $16 \%$, respectively. ${ }^{14-18}$ This is in contrast to the high rates of commercial tobacco use among Aboriginal and Torres Strait Islander peoples in Australia (41\%), First Nations (40\%), Inuit (49\%) and Métis (37\%) peoples in Canada, Māori in Aotearoa (35\%) and American Indian or Alaska Native in the USA (32\%) ${ }^{14-161819}$ which is in each case substantially higher than their nonIndigenous counterparts.

As others have detailed, ${ }^{20} 21$ the Foundation cannot be regarded as independent from its tobacco industry funder, and its work serves to advance the industry's goals. While PMI has claimed it wants to 'end smoking', it continues to promote use of cigarettes. By serving the interests of PMI, the Foundation is complicit in commercial tobacco use and the associated absolute and disproportionate tobacco-related harms to Indigenous peoples. ${ }^{22}$

\section{MODERN COLONISATION}

Colonisation is not a historical artefact and it continues contemporaneously at both country and global levels. Indigenous knowledge, values, behaviours and protocols have been suppressed (or sometimes appropriated) through colonisation processes, implemented by governments, churches 
and other institutions. ${ }^{23-26}$ However, Indigenous peoples remain steadfastly resistant and resilient in the face of colonisation in its many forms. ${ }^{24}$ The global promotion of commercial tobacco and the subsequent addiction of Indigenous peoples to nicotine products is a modern form of colonisation. Colonial forms of oppression include, but are not limited to, forced removal and relocation of Indigenous peoples from their land, removal of Indigenous children and using commercial tobacco as a form of payment prior to engagement with the cash economy. ${ }^{2427}$ For example, tobacco was issued as rations on missions in Australia. ${ }^{27}$ Further, among some Indigenous peoples, the modification, transformation and commercialisation of the nicotiana tobacco plant belittles and disrespects something which is held sacred. ${ }^{25}$ 28-31 Thus, commercial tobacco and any of its derivatives represent a threat to physical health, as well as spiritual health and well-being. In fact, given this understanding regarding the modification, transformation and commercialisation of the nicotiana tobacco plant ${ }^{25} 30$ and the strong evidence base of commercial tobacco-related addiction and ill-health, tobacco industry-funded research activities can be seen as a form of contemporary colonisation. ${ }^{92} 32$ This form of contemporary colonisation can be seen as a result of using culturally inappropriate protocols, assimilative practices and a raft of colonisation tools and processes, distorting Indigenous realities and creating an inaccurate Indigenous narrative that promotes Indigenous health harms and perpetuates oppression.

The tobacco industry's role in purporting to support health research, while also profiting from selling commercial tobacco products, creates a conflict of interest. Therefore, tobacco industry funding of 'health' research either directly or indirectly, including via third parties, should be vigorously resisted. This is underscored by the Framework Convention on Tobacco Control, which states the Parties are "deeply concerned about the high levels of smoking and other forms of tobacco consumption by indigenous peoples" (FCTC, Preamble), ${ }^{22}$ page 2 and urges that tobacco industry influence be resisted.

Others have commented on the disconnect between PMI funding the Foundation as an act of social responsibility and their continued advocacy for, and sales of, tobacco. ${ }^{20} 21$ Further, the effects of the Foundation's funding of the Centre appear to include (1) legitimising the Foundation, including the use of Indigenous imagery in promotional material; (2) legitimising PMI as being a responsible corporate citizen that cares about Indigenous peoples; and (3) creating and exploiting division among Indigenous peoples as well as the health sector by exploiting differences in views around ANDs. While Indigenous views on ANDs are diverse, our lives are complex, and simple individualised solutions, such as targeted smoking cessation interventions delivered in isolation from the larger context of community life, do not necessarily take this complexity into account. ${ }^{33}$

Indigenous peoples experience disproportionately high rates of commercial tobacco use, and consequently disproportionately high rates of tobacco-related death and disease. ${ }^{9}$ PMI appears to be interested in building a veneer of social responsibility, so that it can bolster corporate credibility and leverage this to influence political debates about tobacco control policy. ${ }^{74}$ If PMI was serious about its aims for a smoke-free world, it would cease its opposition to evidencedbased measures to reduce smoking rates, such as advertising bans, tax increases and plain packaging. Further, the tobacco industry would cease commercial tobacco manufacturing, marketing, lobbying and litigation. The tobacco industry has a long history of deliberately colluding in covering up, denying, confusing and questioning the science on smokingrelated morbidity and mortality. ${ }^{35}$ As a business, PMI's goal is to safeguard and extend shareholder profits, thus it is rapidly expanding into the lucrative AND markets. PMI has never demonstrated genuine concern for the health and well-being of Indigenous peoples, and has a history of ignoring and undermining scientific evidence. ${ }^{36}$ The tobacco industry's interest in Indigenous peoples has been to appropriate our names and imagery ${ }^{3137}$ along with the tobacco plant itself, with the sole intent of furthering tobacco sales and profits. Despite this history, the Foundation continues to claim that their agenda is not influenced by PMI. ${ }^{2} 38$ The Foundation states that it "cannot engage in activities designed to support PMI's interests", 2 and is apparently seeking to associate with Indigenous organisations, researchers and peoples worldwide. ${ }^{4}$ But simply by existing and being embedded within PMI's funding strategies, the Foundation is supporting PMI's interests. ${ }^{21}$

Arguably, PMI funds the Foundation to create divisions among those who are working towards a smoke-free world. ${ }^{20} 21$ For example, tobacco industry documents proved that the industry has long known about the health effects of smoking, the danger of secondhand smoke and the addictiveness of nicotine but deliberately colluded in covering up, denying, confusing and questioning the science demonstrating smokingrelated morbidity and mortality. ${ }^{35}$ The arguments about who to trust and who researchers should accept funding from can dilute the health sectors' efforts, create confusion, throw doubt on who should be believed and create further opportunities to promote the tobacco industry agenda. ${ }^{34}$ This replicates a common tool of colonisation: divide and conquer. ${ }^{39}$

\section{HISTORY OF EXPLOITATION AND APPROPRIATION}

PMI has a history of exploiting and appropriating Indigenous names and imagery to sell its products, including selling 'Māori Mix' in Israel. ${ }^{37}$ It also has a long history of opposing sovereign governments implementing tobacco control legislation and policies that will protect the health of their citizens. ${ }^{2035}$ In so doing, PMI exerts its corporate sovereignty over the rights of Indigenous peoples to continue selling tobacco products in their countries, even when they are not wanted. ${ }^{10}$ It is well documented that PMI and the tobacco industry use tactics of focusing on 'individual choice' to redirect blame. However, framing tobacco addiction as 'individual choice' conveniently shifts the policy focus and 'commonsense' discourse away from the issues of tobacco supply and industry profit. ${ }^{34} 40$ For Indigenous peoples, these acts can be seen as attempts to suppress our collective voices. ${ }^{39}$

\section{KA MUA, KA MURI (MĀORI PROVERB: LOOKING TO OUR PAST AS WE MOVE IN THE FUTURE)}

In supporting the Centre, the Foundation President, Dr Derek Yach, released a video in which Indigenous peoples were referred to as 'vulnerable and off the beaten track'. ${ }^{4}$ Indigenous peoples have endured colonisation, but this does not define us. Portraying Indigenous people in a negative light, as marginalised and lacking power, is a classic tool of colonisation. In contrast, for many Indigenous peoples, resilience and resistance have kept our culture alive and our communities are thriving. We hold on to our traditions and the deeds of our ancestors as we move to the future and the potential it holds. 
Indigenous peoples are strong, practical and innovative. We have a range of views on the role of emerging technologies, such as ANDs, in helping achieve our health and wellbeing goals. But the use of ANDs is not and cannot be an end point. Much of the tobacco control discourse extolled by the Foundation sits within a biomedical view of health, focusing on individual physical health. ${ }^{2} 31138$ Indigenous health and well-being is more than physical health ${ }^{11}$-it is about the ways Indigenous people may relate to the tobacco plant, about our spiritual essence, and about fostering an environment for our traditions and culture to prosper. ${ }^{11} 132529$ Committing current and future generations to lifetimes of nicotine dependence has significant health and well-being implications. This is where the Foundation's agenda and PMI's agenda align, and Indigenous health (as well as broader public health) agendas do not. As outlined in the Foundation's Strategic Plan ${ }^{3}$ page 2, they are "...seeking to engage industry to accelerate the shift away from cigarettes towards less harmful forms of nicotine. The ecosystem is capable of transforming today because of innovations in digital consumer technologies and in products that deliver nicotine without the harmful chemicals created by burning tobacco". PMI wants current and future generations to use commercial nicotine products. For Indigenous peoples, our future lies in ridding ourselves from the physical, social and spiritual harms caused by commercial tobacco use and nicotine addiction.

\section{CONCLUSION}

Indigenous peoples should not accept tobacco industry funding. Whether it is explicit or implicit, the tobacco industry will use the Foundation to meet its agenda which is in stark contrast to the health and well-being agendas of Indigenous peoples. Indigenous communities and the public health sector must act now to resist co-optation of Indigenous culture, seek a genuine end to nicotine addiction among our peoples and unify against the industry. The health and well-being of Indigenous peoples is too critical, the promise of future Indigenous generations too important.

\author{
Author affiliations \\ Ngati Hine/Ngapuhi \\ 2Eru Pomare Māori Health Research Unit, Department of Public Health, University of \\ Otago, Wellington, New Zealand \\ ${ }^{3} \mathrm{Ngā} t i$ Raukawa \\ ${ }^{4}$ Department of Public Health, University of Otago, Wellington, Wellington, New \\ Zealand \\ ${ }^{5}$ Ngāti Hauiti \\ ${ }^{6}$ Whakauae Maori Health Research and Development, Auckland, New Zealand \\ ${ }^{7}$ Métis, Métis Nation \\ ${ }^{8}$ Well Living House, Centre for Urban Health Solutions, St. Michael's Hospital, \\ Toronto, Ontario, Canada \\ IUniversity of Toronto Dalla Lana School of Public Health, Toronto, Ontario, Canada \\ ${ }^{10}$ Tyendinega Mohawk First Nation, Haudenosaunee (Iroquois) Confederacy \\ ${ }^{11}$ I-HEART Centre St. Paul's Hospital, Providence Health Care, British Columbia First \\ Nations Health Authority Chair in Heart Health and Wellness, West Vancouver, British \\ Columbia, Canada \\ ${ }^{12}$ Cheyenne River Sioux Tribe (Lakota) \\ ${ }^{13}$ Black Hills Center for American Indian Health, Rapid City, South Dakota, USA \\ ${ }^{14}$ Navajo Nation (Diné) \\ ${ }^{15}$ Modewa Clan \\ ${ }^{16}$ Centre for Research and Action in Public Health, University of Canberra, Canberra, \\ Australian Capital Territory, Australia \\ ${ }^{17}$ Ngiyamppa, (Wongaibon) \\ ${ }^{18}$ National Centre for Epidemiology and Population Health, Australian National \\ University, Canberra, Australian Capital Territory, Australia \\ ${ }^{19}$ Noongar \\ ${ }^{20}$ Faculty of Medicine, Dentistry and Health Sciences, University of Melbourne, \\ Melbourne, Victoria, Australia \\ ${ }^{21}$ Yorta Yorta
}

${ }^{22}$ Wardliparingga Aboriginal Research Unit, South Australian Health and Medical Research Institute and School of Health Sciences, University of South Australia Division of Health Sciences, Adelaide, South Australia, Australia

${ }^{23}$ Vice President (Aboriginal and Torres Strait Islander)—Public Health Association of Australia, Canberra, Australian Capital Territory, Australia

${ }^{24} \mathrm{Co}$-Vice Chair, Indigenous WorkingGroup, World Federation of Public Health Associations

${ }^{25}$ Elder, Kungarakan tribal group and a member of the Iwaidja tribal group ${ }^{26}$ Consultant to the Commonwealth Department of Health, Indigenous tobacco control advocate, Canberra, Australian Capital Territory, Australia

Contributors All authors have contributed substantially to conception, drafting and finalisation of this fundamentally important open letter.

Competing interests None declared.

Patient consent for publicatiopn Not required.

Provenance and peer review Not commissioned; externally peer reviewed.

Open access This is an open access article distributed in accordance with the Creative Commons Attribution Non Commercial (CC BY-NC 4.0) license, which permits others to distribute, remix, adapt, build upon this work non-commercially, and license their derivative works on different terms, provided the original work is properly cited, appropriate credit is given, any changes made indicated, and the use is non-commercial. See: http://creativecommons.org/licenses/by-nc/4.0/.

\section{ORCID iD}

Raglan Maddox http://orcid.org/0000-0002-2770-0686

\section{REFERENCES}

1 Axelsson P, Kukutai T, Kippen R. The field of Indigenous health and the role of colonisation and history. J Popul Res 2016;33:1-7.

2 Foundation for a Smoke-Free World. Our vision: foundation for a smoke-free world, 2018. Available: https://www.smokefreeworld.org/our-vision [Accessed 18 Sep 2018]

3 Foundation for a Smoke-Free World. Strategic plan 2019-2021. New York, USA: Foundation for a Smoke-Free World, 2018.

4 Foundation for a Smoke-Free World. New centre of research excellence launched in New Zealand. Foundation for a Smoke-Free World, 2018.

5 Stephenson K. Proceeds of tobacco pay for research into Indigenous smoking cessation. New Zealand Doctor, 2018.

6 Rose G. Sick individuals and sick populations. Int J Epidemiol 2001;30:427-32.

7 McLaren L, McIntyre L, Kirkpatrick S. Rose's population strategy of prevention need not increase social inequalities in health. Int J Epidemiol 2010;39:372-7.

8 Wilson N, Petrović-van der Deen FS, Edwards R, et al. Modelling the number of quitters needed to achieve New Zealand's Smokefree 2025 goal for Māori and nonMāori. N Z Med J 2018:131:30-7.

9 Maddox R, Waa A, Lee K, et al. Commercial tobacco and Indigenous peoples: a stock take on framework convention on tobacco control progress. Tob Control 2019:28:574-81.

10 Gifford H, Bradbrook S. Recent actions by Māori politicians and health advocates for a tobacco-free Aotearoa/New Zealand, a brief review (occasional paper 2009/1). Wellington: Whakauae Research Services, te Reo Mārama, University of Otago, 2009.

11 Indigenous Health Group. Social determinants and Indigenous health: the international experience and its policy implications. Adelaide, 2007.

12 Kalkhoran S, Glantz SA. E-cigarettes and smoking cessation in real-world and clinical settings: a systematic review and meta-analysis. Lancet Respir Med 2016;4:116-28.

13 Thornley L, Edwards R, Waa A, et al. Achieving Smokefree Aotearoa by 2025 engagement with stakeholders-summary report, 2017.

14 Gionet L, Roshanafshar S. Select health indicators of First Nations people living off reserve. Métis and Inuit: Statistics Canada, 2013.

15 Australian Bureau of Statistics. 2014-15 national Aboriginal and Torres Strait Islander social survey. Canberra, Australia: Australian Bureau of Statistics, 2016.

16 Ministry of Health. Annual data explorer 2016/17. New Zealand Health Survey [Data File], 2017.

17 Smylie J, Firestone M. Back to the basics: identifying and addressing underlying challenges in achieving high quality and relevant health statistics for Indigenous populations in Canada. Stat J IAOS 2015;31:67-87.

18 Centers for Disease Control and Prevention. Current cigarette smoking among adults. Morbidity and Mortality Weekly Report 2018;67:53-9.

19 Smylie J, Anderson M. Understanding the health of Indigenous peoples in Canada: key methodological and conceptual challenges. CMAJ 2006:175:602-02

20 Daube M, Moodie R, McKee M. Towards a smoke-free world? Philip Morris International's new Foundation is not credible. Lancet 2017;390:1722-4.

21 van der Eijk Y, Bero LA, Malone RE. Philip Morris International-funded 'Foundation for a Smoke-Free World': analysing its claims of independence. Tob Control 2018.

22 World Health Organization. WHO framework convention on tobacco control. 44. Geneva: WHO Document Production Services, 2003. 
23 Smith LT. Decolonizing methodologies: research and Indigenous peoples. New York: Zed Books Ltd, 2012.

24 Truth Reconciliation Commission of Canada. Honouring the truth, reconciling for the future: summary of the final report of the Truth and Reconciliation Commission of Canada, 2015.

25 National Native Network. Commercial tobacco—-keeping it sacred, 2018. Available: http://keepitsacred.itcmi.org

26 Paradies Y. Colonisation, racism and Indigenous health. J Popul Res 2016:33:83-96.

27 Cancer Council Victoria. Tobacco in Australia: facts and issues. 3rd edn. Melbourne, 2008.

28 Daley CM, Faseru B, Nazir N, et al. Influence of traditional tobacco use on smoking cessation among American Indians. Addiction 2011;106:1003-9.

29 Boudreau G, Hernandez C, Hoffer D, et al. Why the world will never be tobacco-free: reframing "tobacco control" into a traditional tobacco movement. Am J Public Health 2016;106:1188-95.

30 Winter JC. Tobacco use by native North Americans: sacred smoke and silent killer. University of Oklahoma Press, 2000.

31 D'Silva J, O'Gara E, Villaluz NT. Tobacco industry misappropriation of American Indian culture and traditional tobacco. Tob Control 2018:27:e57-64.

$32 \mathrm{McCambridge} \mathrm{J.} \mathrm{Ethical} \mathrm{issues} \mathrm{raised} \mathrm{by} \mathrm{tobacco} \mathrm{industry-linked} \mathrm{research} \mathrm{in} \mathrm{the} \mathrm{era} \mathrm{of}$ e-cigarettes. Addiction 2016;111:1334-5.

33 Ermine WJ. A critical examination of the ethics in research involving Indigenous peoples. Canada: University of Saskatchewan Saskatoon, 2000.
34 Friedman LC, Cheyne A, Givelber D, et al. Tobacco industry use of personal responsibility rhetoric in public relations and litigation: disguising freedom to blame as freedom of choice. Am J Public Health 2015:105:250-60.

35 Francey N, Chapman S. "Operation Berkshire": the international tobacco companies' conspiracy. BMJ 2000;321:371-4.

36 Cummings KM, Morley CP, Hyland A. Failed promises of the cigarette industry and its effect on consumer misperceptions about the health risks of smoking. Tob Control 2002;11(suppl 1):i110-7.

37 Herald NZ. Māori mix cigarettes in Israel ignites row. New Zealand: New Zealand Herald, 2005.

38 World Health Organization. Who statement on Philip Morris funded foundation for a smoke-free world, 2017. Available: http://www.who.int/news-room/detail/28-092017-who-statement-on-philip-morris-funded-foundation-for-a-smoke-free-world

39 Banerjee SB. The practice of stakeholder colonialism: national interest and colonial discourses in the management of Indigenous stakeholders. In: Prasad A, ed. Postcolonial theory and organization analysis: a critical engagement. New York: Palgrave Macmillan, 2003: 255-82.

40 Balbach ED, Smith EA, Malone RE. How the health belief model helps the tobacco industry: individuals, choice, and "information". Tob Control 2006;15(Suppl IV):iv37-43. 